\title{
Effect of Colchicine treatment on the cariology and morphology signs of Polemonium caeruleum L.
}

\author{
Alina Glazunova ${ }^{1, *}$, Firdaus Hazieva ${ }^{1}$, and Tatiana Samatadze ${ }^{2}$ \\ ${ }^{1}$ Russian State Medicinal and Aromatic Plants Research Institute, Moscow 117216, Russia \\ ${ }^{2}$ Engelhardt Institute of Molecular Biology, Russian Academy of Sciences, 119991 Moscow, Russia
}

\begin{abstract}
The effect of colchicine treatment of $P$. caeruleum on morphological and economically valuable traits, pollen size and fertility, and karyotype of also was studied. Colchicine treatment increased in the size of pollen by $13 \%$ compared to the control, pollen fertility decreased by $19 \%$. Stained chromosomes of the karyotype were identified, their sizes were determined for the first time, and karyotype formulas for diploid $K=(5 m+2 s m+2 s t)$ and tetraploid forms $K=2(10 m+4 s m+4 s t)$ were compiled. As a result of colchicine treatment, the plant height decreased by $35 \%$, the stem thickness by $47 \%$, the number of generative shoots $18 \%$, the leaf length $23 \%$ and width increased $22 \%$, compared to the control. The productivity of raw by $32 \%$ and seeds of tetraploid plants exceeds diploid plants by $22 \%$.This research was supported government as signment (No. 0576-2019-0008).
\end{abstract}

\section{Introduction}

Polemonium coeruleum L. - perennial herbaceous herbal plant of Polemoniaceae, height $35-120 \mathrm{~cm}$.

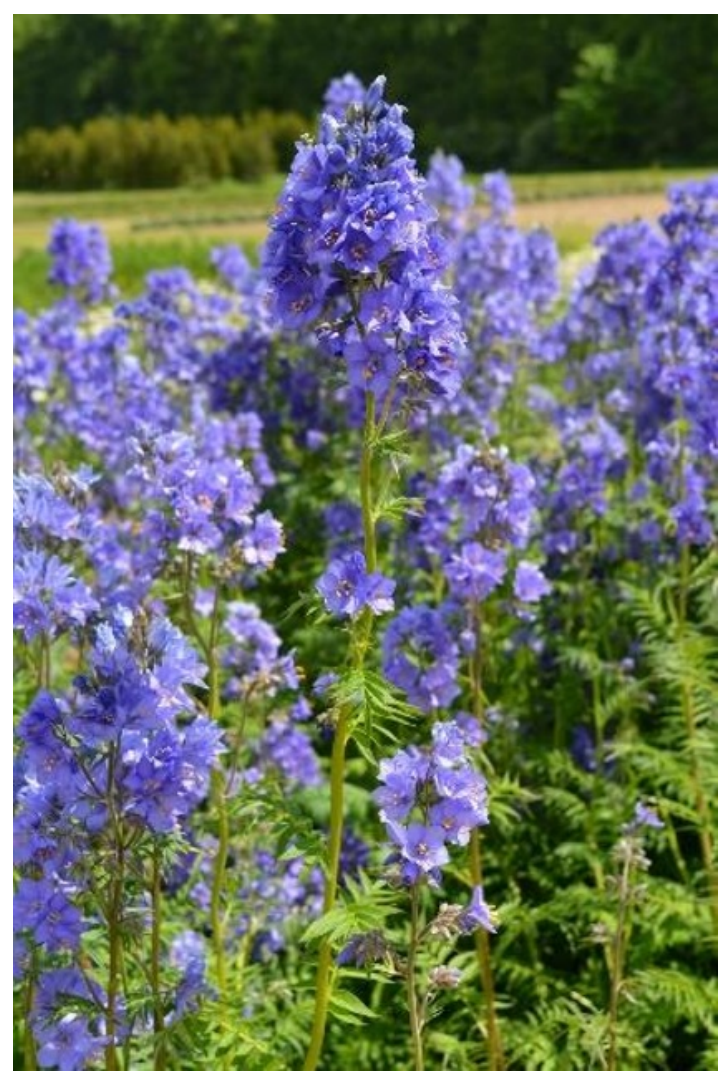

Fig. 1. Polemoniumcaeruleum
The flowers are large, bright blue, (rather white), the stem is hollow, solitary, straight (Fig. 1). It blooms from the second year of life, in the first half of summer for 15-20 days. The plant is quite widespread in central Russia.

The plant was recognized as a medicinal herb in ancient Greece where it was known as «Greek valerian» or «Jacob's Ladder». The roots were used for treat dysentery, toothaches and animal bites [1-3]. However, $P$. caeruleum recently entered medicine. M.N. Varlakov had investigated the medicinal flora of Eastern Sayan Mountains in northern Mongolia and studied this plant in 1932.

The author proposed $P$. caeruleum as an expectorant remedy to replace imported Polygala senega [4]. P. caeruleum also had found in European pharmacies during the XIX century and used as an antisyphilitic agent and for treating rabies [5]. Due to numerous applications, this plant is important in traditional Chinese and Russian medicine.

The rhizomes with roots of $P$. caeruleum (Fig. 2) contain triterpene saponins, olean an derivatives in the polymonioside $\mathrm{C}$ form, anthocyanins and carotenoid pigments, (polymoniumenin A, polymoniogenin, kameliagenin E, Aasemogeninol , barringtogenol $\mathrm{C}$ and R-1-barygenol and Polemoniumsaponin 1, 2, 3 [6, 7].

These compounds have a wide spectrum of activity: antioxidant, antitumor, anti-inflammatory, antiatherogenic, diuretic, antifungal, antiviral, antiarrhythmic and d toxic $[8,9]$. The active ingredients are the triterpene pentacyclic saponins of the $\beta$-amrin group (polymonosides), whose aglycones are predominantly esters of highly hydroxylated triterpene

\footnotetext{
* Corresponding author: alina.glazunova@ outlook.com
} 
alcohols and acetic, tiglinic, angelic, and methylbutyric, propionic and isobutyl acids.

The flavonoids predominate in the aerial part, carbohydrates, fatty acid esters, amino acids and carboxylic acids are present. Rhizomes with the roots of cyanosis - Rhizomata cum radicibus Polemonii (Fig. 2), are included in the Global Fund XI as an expectorant. The antibacterial activity of the aerial part of $P$. caeruleum against $E$. coli was detected [10].

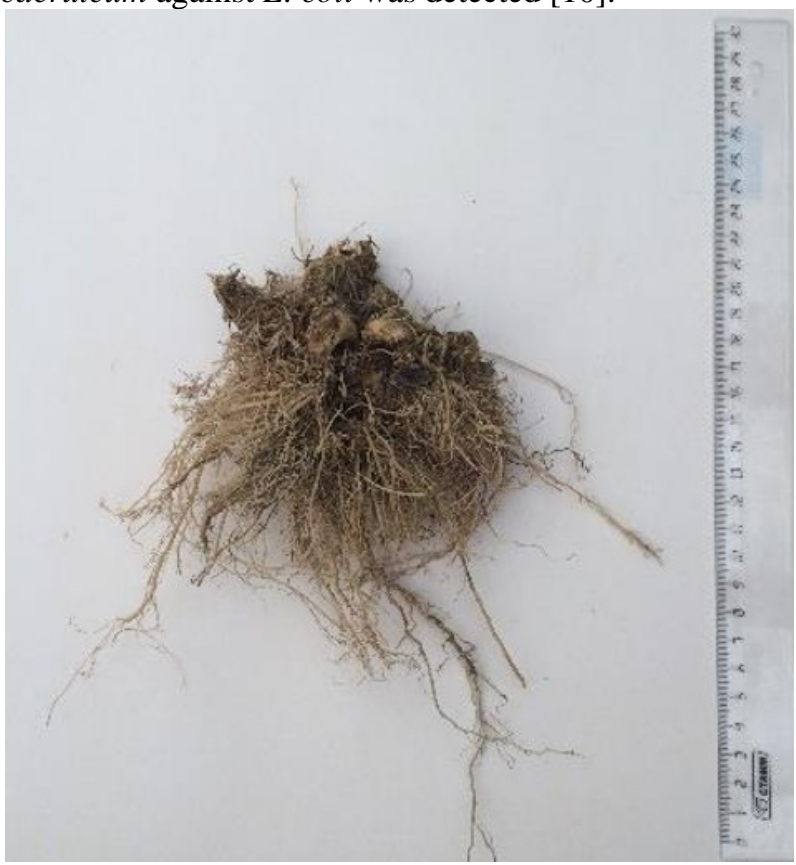

Fig. 2. Polemonium caeruleum rhizomes with roots

In the last decade, there were more than 2543 mutant cultivars derived from 175 plant species including ornamentals, cereals, oilseeds, pulses, vegetables, fruits, and fibers released in 50 countries worldwide [11]. Chemical mutagenesis is a simple approach used to create a mutation in economically valuable plants, for improvement of their agronomic parameters. In any mutation-breeding program, the selection of an effective and efficient mutagen is essential to produce a high frequency of desirable mutations [12]. Many chemical mutagens have been employed to obtain useful mutants in various crop species [13].

A chemical mutagenesis is a simple approach that is used to produce mutations in economically valuable plants, to improve their useful economic characteristics. Experimental polyploidy and mutagenesis methods are widely used in a selection of not only agricultural crops, but also of medicinal crops.

As a result of exposure on seedlings with a $0.2 \%$ aqueous solution of colchicine (24 hours exposure) Matricaria chamomilla tetraploid variety "Podmoskovnaya" was develop $(2 \mathrm{n}=36)$. Valeriana officinalis variety "Uliyana" also obtained by treatment seeds of $0.035 \%$ NEM solution about 18 hours of exposure. Datura stramonium variety "Beshipny" was obtained as a result of treatment seedlings with a $0.2 \%$ solution of colchicine [14].
Two new varieties of Calendula officinalis the "Zolotoe more" and the "Rajskij sad" was develop by colchicines treatment [15].

\section{Materials and methods}

The studies were conducted in 2018-2019 in the laboratory, in the greenhouse complex, on the experimental field of the Department of Agrobiotechology of Russian State Medicinal and Aromatic Plants Research Institute according to the methods adopted for working with medicinal plants.

To obtain polyploids, the seeds were germinated in Petri dishes on filter paper at temperature $+22{ }^{\circ} \mathrm{C}$. When the roots of seedlings reached the $2 \mathrm{~mm}$, seedlings were placed in a $0.2 \%$ colchicine solution for 12 hours and then washed in water.

After the appearance of cotyledon leaves, they were transplanted in a box and placed in a greenhouse; in the phase of 4-5 leaves, the plants were planted in a field according to a $60 \times 30 \mathrm{~cm}$ pattern.

The experiment was repeated 4 times. The soil of the experimental plot is heavy loamy with the content (in terms of absolutely dry matter): humus - up to $4.31 \%$, total nitrogen $0.068-0.072 \%, \mathrm{P}_{2} \mathrm{O}_{5}-0.1 \%, \mathrm{~K}_{2} \mathrm{O}-$ $2.9-3.5 \%, \mathrm{Al}_{2} \mathrm{O}_{3}-15.0 \%, \mathrm{Na}_{2} \mathrm{O}-1.4 \%, \mathrm{MgO}-$ $1.0 \%$, aqueous $\mathrm{pH} 6.1-6.4$.

Fertility and size of pollen were studied on temporary acetocarmine preparations in 50 fields of view in 4-fold reiteration by the method [16]. To count the number of chromosomes and analyze karyotypes, rosette of basal leaves were fixed in a solution of acetic alcohol (3: 1) and preparations were prepared according to the method of [16].

Scanning preparations for measurement the diameter of pollen and was carried out using a Lomo Mikmed-5 light microscope equipped with a 14.0 megapixel USB 2.0 C-Mount camera. For chromosome analysis, at least 5 preparations were used and at least 70 cells were analyzed.

Biometric measurements were carried out during the phase of flowering and during the ripening of seeds. To determine the yield of raw materials, the roots of the plants were dug out at the end of the growing season (2-3 of September), washed in water and dried at a temperature of $40{ }^{\circ} \mathrm{C}$ for 72 hours. The content of saponins in the raw materials was determined according to State Pharmacopy paragraph 2.5.0039.15.

\section{Results}

\subsection{Pollen characteristics}

The pollen of Polemonium caeruleum is multi-pore and spherical. Diameter of pollen grains is the 52.8-59.4 microns. Round in outline. The pores are round or slightly elongate up to $3 \mu \mathrm{m}$ in diameter with caps, the edges of the pores are sinuous. Color of pollen grains is dark yellow [17]. 
Morphological characteristics, the diameter of pollen of the control diploid variant $(2 n=18)$ and tetraploid showed that the treatment of seeds with colchicine increased the size of pollen grains by $13 \%$ compared to the control, pollen fertility decreased by $19 \%$ (Table 1; Fig. 3).

Table 1. Morpho-physiological characteristics of the pollen

\begin{tabular}{|c|c|c|c|}
\hline $\begin{array}{c}\text { Type of the } \\
\text { experiment }\end{array}$ & \multicolumn{2}{|c|}{ Size of pollen grains, $\mu \mathrm{m}$} & \multirow{2}{*}{$\begin{array}{c}\text { Pollen } \\
\text { fertility, } \%\end{array}$} \\
\cline { 2 - 3 } & mean & $\begin{array}{c}\text { limits of } \\
\text { variation }\end{array}$ & \\
\hline Control & $44.2 \pm 1.54$ & $38.3-50.4$ & $95.5^{*} \pm 0.95$ \\
\hline Colchicine & $\begin{array}{c}53.7^{*} \pm 1.5 \\
6\end{array}$ & $50.5-61.7$ & $76.1 \pm 2.42$ \\
& & \\
\hline
\end{tabular}

*Values are significantly different at $\mathrm{P} \leq 0.05$.

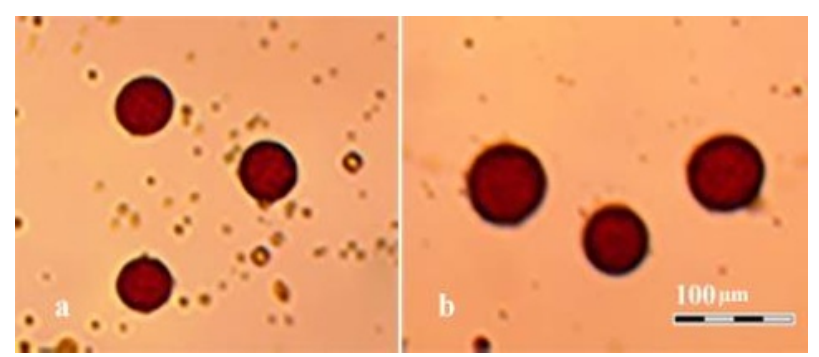

Fig. 3. Difference between size pollen grains: $a-$ control; b colchicine treatment

\subsection{Karyotyping}

As a result of karyological studies, the numbers of monochromatic chromosomes, morphometric parameters and types of chromosomes in the studied forms of cyanosis were determined. It was revealed the karyotype in the initial form is diploid $(2 n=18)$, the chromosomes are medium in size and range from 3.6 to $5.0 \mu \mathrm{m}$ (Fig. 2a). The karyotype is represented by metacentric chromosomes (from 1 to 7 ), with 1 and 3 chromosomes being a satellite, as well as submetacentric chromosomes (8 and 9) (Fig. 2c). Karyotype formula:

$$
\mathrm{K}=\left(5 m+2 s m+2^{\mathrm{st}}\right)
$$

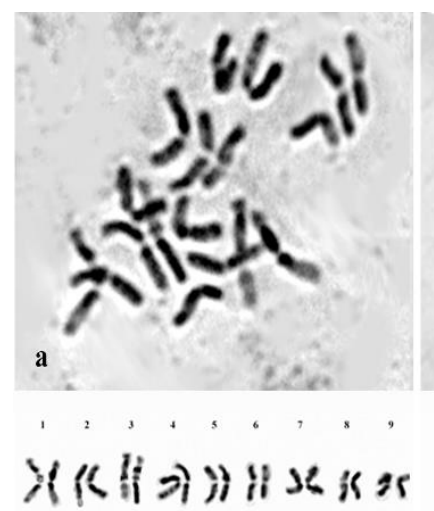

c

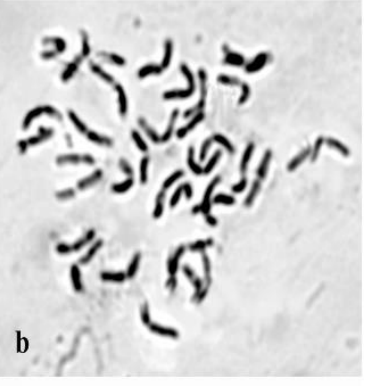

$\|x(\mathrm{tin}) x\| \| x$

) $x$ if $x$ x $\|\pi\|$

d

Fig. 4. Chromosomes at mitotic metaphase (a, b) and karyotypes $(\mathrm{c}, \mathrm{d})$ of $P$. caeruleum: a, $\mathrm{c}$ diploid $\mathrm{K}=$ $\left(5 \mathrm{~m}+2 \mathrm{sm}+2^{\mathrm{st}}\right) ; \mathrm{b}, \mathrm{d}$ tetraploid $\mathrm{K}=2\left(10 \mathrm{~m}+4 \mathrm{sm}+4^{\mathrm{st}}\right)$.

It was established the karyotype of the form of cyanosis treated with colchicine is tetraploid $(2 n=4=36)$ with chromosome sizes from 3.0 to 4.4 microns. (Fig. 2b).

The karyotype is represented by metacentric chromosomes (1-7; 10-16), with $1,3,10,12$ being a satellite, as well as submetacentric chromosomes (8, 9, 17, 18) (Fig. 4d). Karyotype formula:

$$
\mathrm{K}=2\left(10 m+4 s m+4^{\mathrm{st}}\right)
$$

\subsection{Morphometric and economically valuable characteristics}

It was revealed tetraploid plants significantly differ from diploid plants in morphological characters. The plants are undersized, characterized by a large number of shoots with anthocyanin-color and greater thickness stems than control plants. The leaves of the tetraploids are larger, have a dark green color (Table 2). It was found flowering in tetraploid forms of plants is a week later than the control diploid forms.

Table 2. Effect of Colchicine treatment on morphometric signs

\begin{tabular}{|c|c|c|}
\hline Parameters & Control & Colchicine \\
\hline Plant height, cm & $71.3 \pm 3.31^{*}$ & $46.3 \pm 2.31$ \\
\hline $\begin{array}{c}\text { Amount of generative shoots, } \\
\text { pcs. }\end{array}$ & $6.1 \pm 0.50$ & $7.2 \pm 0.88^{*}$ \\
\hline Stem thickness, cm & $0.68 \pm 0.064$ & $1.00 \pm 0.094^{*}$ \\
\hline Leaf length, cm & $17.7 \pm 1.11$ & $21.8 \pm 0.44^{*}$ \\
\hline Leaf width, cm & $6.4 \pm 0.24$ & $7.8 \pm 0.68^{*}$ \\
\hline
\end{tabular}

*Values are significantly different at $\mathrm{P} \leq 0.05$.

As a result of colchicine treatment the plant height decreased by $35 \%$, the stem thickness, the number of generative shoots, the leaf length and width increased by $47,18,23$, and $22 \%$, respectively, compared to the control. The decrease in plant height during colchicine treatment coincides with the results of K.P.M. Dhamaynthi and Vinita Gotmare [18].

The yield of raw materials and seeds of plants grown from seedlings treated with colchicine is observed due to increase in the number of shoots and leaf size. The productivity of air-dried raw materials significantly exceeded the same indicator in diploid plants by $60 \%$, seed productivity by $31.8 \%$.

Table 3. Effect of colchicine treatment on the root and seeds yield

\begin{tabular}{|c|c|c|}
\hline Characteristic & Control & Colchicine \\
\hline $\begin{array}{c}\text { Raw productivity (rhizomes } \\
\text { with roots) gram/plant }\end{array}$ & $36.5 \pm 3.33$ & $48.3 \pm 4.71^{*}$ \\
\hline Seed productivity, gram/plant & $8.7 \pm 0.56$ & $10.7 \pm 1.28^{*}$ \\
\hline Saponin content, $\%$ & $15.1 \pm 1.05$ & $15.5 \pm 1.05$ \\
\hline
\end{tabular}

Values are significantly different at $\mathrm{P} \leq 0.05$.

Colchicine treatment has not much effect on biologically active compounds.

Seeds collected from tetraploid plants are characterized by reduced germination; however, colchicine treatment increased the weight of 1000 seeds by $5.5 \%$ (Fig. 5 and 6 ). 


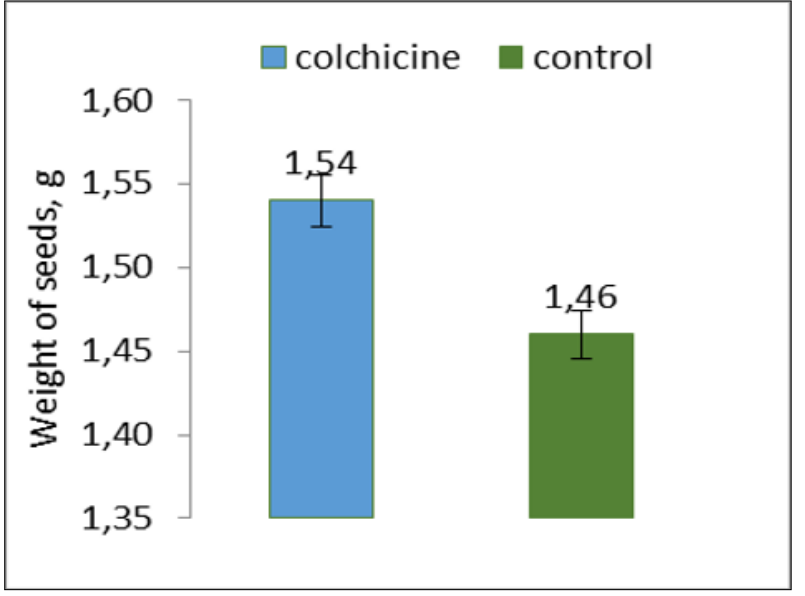

Fig. 5. Weight of 1000 seeds, g

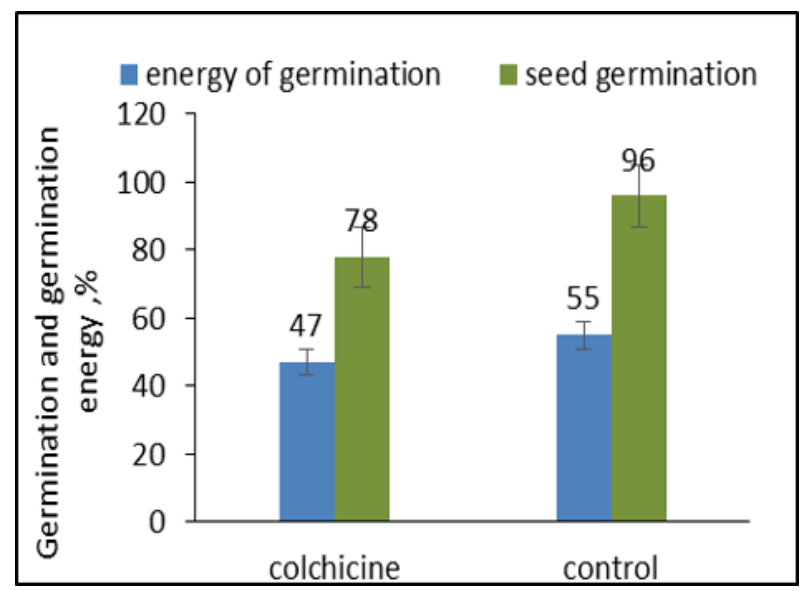

Fig. 6. Sowing qualities of seeds germination energy and seed germination $(\%)$

\section{Conclusion}

For the first time, chromosomes of the karyotype Polemonium caeruleum L. were identified by color patterns in accordance with the cytological classification of chromosomes. Based on the re-obtained results, karyotype formulas for the diploid and tetraploid forms were compiled. Tetraploid plants are compact, large stems and their thickness, large leaf sizes, which significantly leads to an increase in the yield of raw materials and seeds.

\section{References}

1. M. Blumenthal, Herbal Medicine: Expanded Commission E, Monographs (2000)
2. M. Blumenthal, American Botanical Council (Austin, Texas, 2003)

3. M. Wicht, Herbal Drugs and Phytopharmaceticals (Medpharm, Stuttgart, 2004)

4. A.D. Turova, E.N. Salozhnikova, Medicinal Plants of the USSR and Their Use, 43-45 (Meditsina, Moscow, 1983)

5. K.G. Ramawat, J.-M. Mérillon (Springer, 2013)

6. A.A. Malštseva, A.A. Sorokina, T.A. Brezhneva, A.S. Chistyakova, A.I. Slivkin, Farmatsiya, 7, 13-16 (2011) Retrieved from: https://www.scopus.com/record/display.uri?eid=2s2.0-85061705048\&origin=inward

7. P.V. Myslennikov, G.N. Chupakhina, L.N. Skrypnik, Biol. Bull., 41, 133-138 (2014)

8. J.M. Augustin, V. Kuzina, S.B. Andersen, S. Bak, Phytochemi., 72, 435-457 (2011)

9. L. Di Marzio, C.A. Ventura, D. Cosco, D. Paolino, A. Di Stefano, R. Stancanelli, S. Tommasini, C. Cannavà, C. Celia, M. Fresta, J. Drug Deliv. Sci. Technol., 32, 174-191 (2016) Retrieved from: https://doi.org/10.1016/j.jddst.2015.10.011

10. G. Łaska, E. Sieniawska, Ł.Świątek, J Zjawiony, S. Khan, A. Boguszewska, M. Stocki, M. Angielczyk, M. Polz-Dacewicz, Phytochem. Letters, 30, 314-323 (2019) Retrieved from: https://doi.org/10.1016/j.phytol.2019.02.017

11. V.L. Chopra, Curr. Sci., 89, 353-359 (2005)

12. R. Roychowdhury, J. Tah, Curr. Bot., 2, 19-23 (2011)

13. Y.I. El-Nashar, A.A. Asrar, Genet. Mol. Res., 15, 1-14 (2016) Retrieved from: https://doi.org/10.4238/gmr.15028071

14. N.I. Sidel'nikov, F.M. Hazieva, A.I. Morozov, Kuban State Agrar. Univer. named after I.T. Trubilin Bulletin, 59, 337-343 (2016)

15. T.E. Samatadze, S.A. Zoshchuk, F.M. Hazieva, O.Yu Yurkevich, N.Yu Svistunova, A.I. Morozov, A.V. Amosova, O.V. Muravenko, Sci. Reports, (2019) Retrieved from: https://doi.org/10.1038/s41598-019-45738-3

16. Z.P. Pausheva, Practical lessons of plant cytology (Kolos, Moscow, 1980)

17. A.N. Burmistrov, V.A. Nikitina, Melliferous plants and their pollen, a handbook (Rosagropromizdat, Moscow, 1990)

18. K.P.M. Dhamaynthi, V. Gotmare, J. of Plant Breed., 1(4), 966-972 (2010) 